\title{
Mole-rats act as ecosystem engineers within a biodiversity hotspot, the Cape Fynbos
}

\author{
N. Hagenah ${ }^{1, *} \&$ N.C. Bennett ${ }^{1}$ \\ ${ }^{1}$ Mammal Research Institute (MRI), Department of Zoology \& Entomology, University of Pretoria, Pretoria \\ 0002, South Africa \\ * Corresponding author. Present address: School of Life Sciences, University of KwaZulu-Natal, Private \\ Bag X01, Scottsville, Pietermaritzburg 3209, South Africa. Email: Hagenah@ukzn.ac.za
}

\begin{abstract}
Through their burrowing and foraging activities, subterranean rodents disturb large amounts of soil. As a result, they may modify physical and chemical soil properties and thus change the productivity, structure and dynamics of plant communities. To date, research on the ecological importance of fossorial mammals has focussed predominantly on subterranean rodents in North and South America, Europe and Asia. Surprisingly, despite the potential of them filling a similar ecological niche, very few studies have focussed on the impacts of mole-rats (Bathyergidae) in Africa. To determine how mole-rats modulate their environment, we examined the soil and vegetation properties of mole-rat-modified habitats in the Cape Floristic Region, South Africa. We predicted that excavation would result in mound soils having higher nutrient levels, more uniform soil particle profiles and lower compactness compared to undisturbed soils. Furthermore, we expected their digging and foraging activities would
\end{abstract}


change plant species composition and increase plant productivity and diversity. As predicted, we found that soils disturbed by mole-rats had higher nutrient levels and lower compactness compared to undisturbed soils, and an altered plant species composition. However, in contrast to our predictions, mounds had a finer particle size profile, and mole-rat burrowing and foraging lowered the overall aboveground plant biomass. Most importantly, the presence of mole-rats enhanced plant species richness. However, as disturbance increased plant species richness declined. Our findings suggest that in Africa, mole-rats fulfil the same ecological niche as their ecological cognates in other ecosystems and thus ultimately act as ecosystem engineers.

Key words: Bathyergidae, Cape Floristic Region, ecosystem engineer, fossorial mammals, soil disturbance, South Africa, subterranean rodents.

\section{Introduction}

Burrowing by subterranean rodents can have important impacts on soil and vegetation, and thus ultimately on ecosystem properties and processes (e.g., Reichman \& Seabloom, 2002). Their digging and mounding activities can profoundly alter chemical and physical soil properties as they search for food and/or mates, or during dispersal (Kerley, Whitford \& Kay, 2004). Studies in North America indicate that the excavations of subterranean rodents affect soil nutrient availability and heterogeneity (e.g., Huntly \& Inouye, 1988). Mound soils can have either higher or lower nutrient levels compared to undisturbed soils (e.g., Andersen \& MacMahon, 1985; Spencer et al., 1985). 
Additionally, mound soils generally have more uniform particle size profiles and lower bulk densities than undisturbed soils (Jackson et al., 2007).

Subterranean rodents can also alter vegetation characteristics by modifying plant productivity, composition and diversity (Huntly \& Inouye, 1988). For instance, mounds may act as nutrient 'hotspots' and thus represent an improved resource environment for plants (Williams \& Cameron, 1986). This could increase plant growth and encourage colonisation of plants (Desmet \& Cowling, 1999). On the other hand, by excavating soil, animals may bury vegetation and thus reduce aboveground vegetation (Jones, Halpern \& Niederer, 2008). Furthermore, burrowing activities can create a dynamic mosaic of nutrient conditions thereby promoting plant species diversity (e.g., Spencer et al., 1985). Finally, foraging and selective feeding of preferred plant species can also impact biomass and species composition (Inouye et al., 1987).

To date, research on the ecological importance of subterranean rodents has focussed predominantly on species in North and South America, Europe and Asia (e.g., Grant, French \& Folse, 1980; Zhang, Zhang \& Liu, 2003; Lara, Sassi \& Borghi, 2007). Due to the extent of their impacts, these species are generally considered to be 'ecosystem engineers' (e.g., Reichman \& Seabloom, 2002). However, despite their morphological and behavioural similarity, very few ecological studies have been conducted on mole-rats (Bathyergidae) within African biomes (Reichman \& Jarvis, 1989). As these species may fulfil the same ecological niche, they too may act as 'ecosystem engineers'.

Mole-rats of the family Bathyergidae are subterranean rodents which are endemic to Africa (Skinner \& Chimimba, 2005). Like many other subterranean rodents, mole-rats 
excavate and maintain extensive burrow systems and subsequently deposit soil mounds on the ground surface (Bennett \& Faulkes, 2000). Mole-rats are herbivorous, feeding mostly on plant storage organs such as roots, bulbs and tubers (Bennett \& Faulkes, 2000). Two species of bathyergids, the common mole-rat (Cryptomys hottentottus hottentottus) and the Cape mole-rat (Georychus capensis), occur sympatrically in a unique area of the Cape Floristic Region of South Africa (Lovegrove \& Jarvis, 1986). The Cape Floristic Region comprises one of the world's richest flora diversity and is recognised as a biodiversity hotspot of global significance (Goldblatt, 1997).

To understand the ecological niche of mole-rats, we examined the soil and vegetation characteristics of mole-rat-modified habitats in the Cape Floristic Region, South Africa. We predicted that:

1) Mound soils would have higher nutrient concentrations compared to undisturbed soils due to decomposed uneaten food combined with excrement.

2) Mole-rat burrowing activities would result in mound soils having more uniform particle size profiles and lower compactness than undisturbed soils.

3) The improved resource environment generated by mole-rats would increase plant productivity.

4) Mole-rats would change the plant species composition due to their burrowing and foraging activities.

5) Plant species richness in mole-rat habitats would increase by the enhanced resource heterogeneity. 
6) Mole-rats may act as ecosystem engineers similar to their ecological kin on other continents.

\section{Materials and methods}

\section{Study area}

We conducted the study at the 'Wayland' Flower Reserve, Darling $\left(33.25^{\circ} \mathrm{S}, 18.25^{\circ} \mathrm{E}\right)$, approximately $60 \mathrm{~km}$ north of Cape Town in the Western Cape, South Africa. The annual average temperature ranges between $11{ }^{\circ} \mathrm{C}$ and $24{ }^{\circ} \mathrm{C}$, while the mean annual rainfall is $471 \mathrm{~mm}$ (South African Weather Service 2008). Precipitation is strictly seasonal with most occurring between June and August. The reserve ( $80 \mathrm{ha})$ is located in the centre of the lowland sand plain and Renosterveld fynbos. Vegetation in the reserve comprises more than 300 species of flowering plants (Manning \& Goldblatt, 2007), including numerous geophytes ( e.g., Geissorhiza and Micranthus) and two prominent grass species (Paspalum and Bromus). Cattle and sheep graze within the reserve from October until May. Grazing is restricted throughout the rest of the year to allow flowers to grow. Both cattle and sheep graze predominantly in the dry areas of the reserve (N. Hagenah, pers. observation).

Two mole-rat species occur in the study area, the solitary Cape mole-rat (Georychus capensis) and the social common mole-rat (Cryptomys hottentotus hottentotus). Common mole-rats range between $57-81 \mathrm{~g}$, while Cape mole-rats are between 188-211 g (N. Hagenah, unpubl. data). Both species excavate subterranean burrows with their incisors and deposit soil mounds on the ground surface. The mean volume of soil in Cape mole-rat mounds is $2,150 \mathrm{~cm}^{3}$ compared to $1,470 \mathrm{~cm}^{3}$ for 
common mole-rat mounds (Reichman \& Jarvis, 1989). At a large scale, the mounds of both species may cover as much as $39 \%$ of the ground within landscapes. This is similar to the effect that pocket gophers can have on landscapes in North America (Inouye et al., 1987). Both mole-rat species occur in areas with compact clay soils but also utilise sandy loams and alluvium (Skinner \& Chimimba, 2005). In our study, the Cape mole-rat occurred in an area that was particularly wet. As a result, mole-rat species and habitat covary. Thus, we limit our analysis and discussion to the impacts of the different mole-rat species within their respective habitats. To do this, we only include habitat and not mole-rat species in the different analyses. We refer to the habitat of Cape mole-rats as 'wet' and to the habitat of the common mole-rats as 'dry' hereafter.

\section{Data collection}

\section{Chemical soil properties}

We collected soil samples from 15 fresh mounds per mole-rat species. To compare these with undisturbed areas, we took a corresponding sample for each mound from undisturbed soil $5 \mathrm{~m}$ away from each mound. The nitrogen $(\mathrm{N})$, phosphorus $(\mathrm{P})$, calcium $(\mathrm{Ca})$, potassium $(\mathrm{K})$, magnesium $(\mathrm{Mg})$ and sodium $(\mathrm{Na})$ concentrations of these soil samples were then determined in the lab.

\section{Physical soil properties}

For each soil sample ( $\mathrm{N}=60)$, we oven-dried and then vibrated a $500 \mathrm{~g}$ subsample through a series of nine sieve sizes for $10 \mathrm{~min}$. We then weighed the individual sieve size contents and calculated the relative proportions of particle size distributions of each 
sample. In a different area of the reserve to where we collected the soil samples, we conducted soil compactness readings. We did this, as data collection for one set of samples would not affect the data from the other. To determine soil compactness, we used a penetrometer (Eikelkamp Agricultural Instruments, Geisbeek, the Netherlands). We took 20 compactness readings per mole-rat species for each of the four categories: 1) fresh mounds (soil clods were still moist and soft), 2) old mounds (soil clods were dry and hard), 3) mound vicinity (within 1-2 m distance from mounds so as to see if impacts went beyond the mound itself), and in 4) intermound areas (located at least $5 \mathrm{~m}$ distance to any mounds, to represent the undisturbed soil within an area utilised by mole-rats). Although the exact time since the last soil disturbance by mole-rats for 'intermound areas' (category 4) was impossible to determine, measurements were only taken where there was either no burrow systems or old mounds.

\section{Vegetation data on large and small spatial scales}

We determined vegetation characteristics away from where we collected soil data to ensure that the collection of one type of data did not affect the results of the other. For each habitat type (dry habitat: common mole-rats; wet habitat: Cape mole-rats), we created ten $5 \times 5 \mathrm{~m}$ plots in areas of high mole-rat activity. To ensure that each plot with mounds represented an individual burrow system, plots were separated by $10 \mathrm{~m}$, which corresponds to the distance between burrow systems (N. Hagenah, unpubl. data). Each plot containing mounds had a corresponding plot without mounds less than $3 \mathrm{~m}$ away. Plots without mounds acted as control areas of undisturbed soil. Within each plot, we then haphazardly distributed eight $0.5 \times 0.5 \mathrm{~m}$ quadrats (Fig. 1). Naturally, plots with 
Mole-rats present

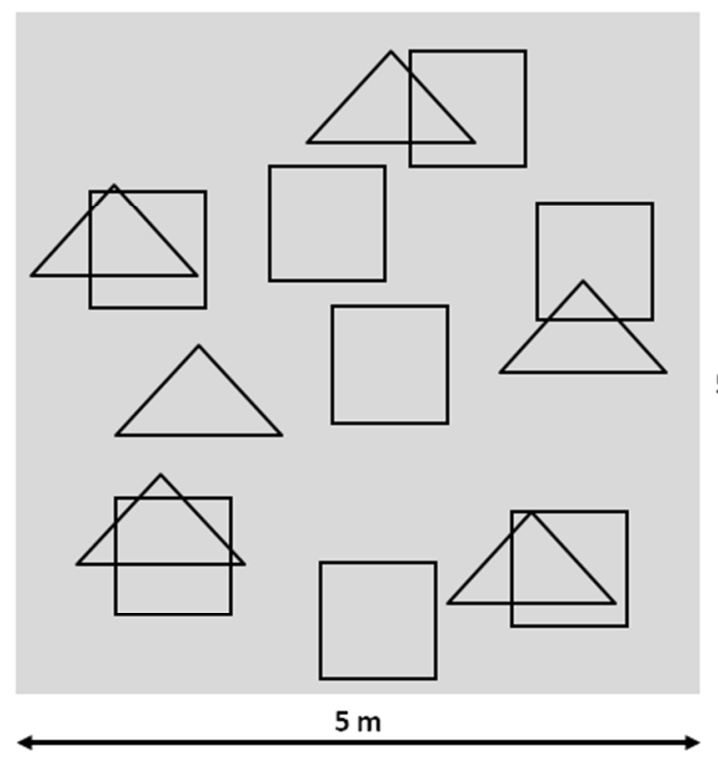

Mole-rats absent

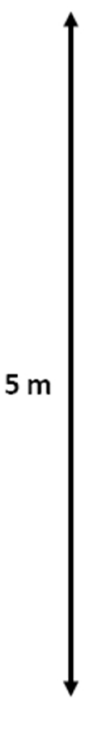

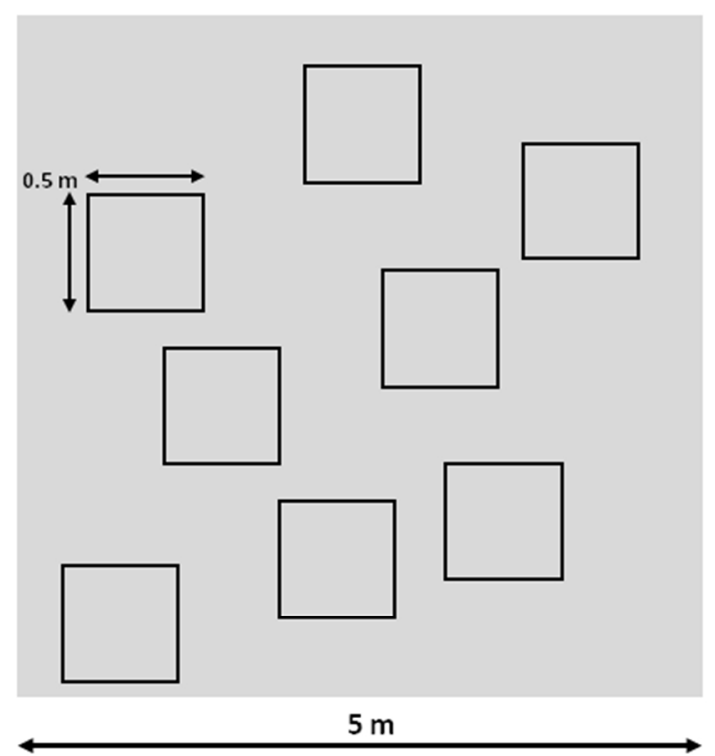

Figure 1 Experimental set-up of the study conducted at the 'Wayland Flower Reserve', Darling, South Africa. Large $5 \times 5 \mathrm{~m}$ plots represent areas with mole-rats and corresponding plots without mole-rats. Mole-rat mounds are indicated as triangles. Eight $0.5 \times 0.5 \mathrm{~m}$ quadrats were haphazardly distributed within each $5 \times 5 \mathrm{~m}$ plot. Plots with mounds included quadrats with and without mounds.

mounds included quadrats with and without mounds. In each quadrat, we recorded all plant species present. We then clipped all the aboveground plant biomass and ovendried it for 24 hours at $60{ }^{\circ} \mathrm{C}$ to determine net primary production. To correlate the strength of the disturbance with its effect on the vegetation, we recorded the number of mounds in all plots that included mounds. Furthermore, for quadrats with mounds, we calculated the proportion of the area covered by mounds. 


\section{Statistical analysis}

At the broadest scale, we compared the two habitats in which the different mole-rat species occurred. To do this, we limited our analysis to data obtained from the undisturbed areas. We first used $t$-tests to determine whether the different soil nutrients (i.e. $\mathrm{N}, \mathrm{P}, \mathrm{Ca}, \mathrm{K}, \mathrm{Mg}, \mathrm{Na})$ and compactness $(\mathrm{kN} / 50 \mathrm{~mm})$ varied between the habitats (dry, wet). We then used a 2-way ANOVA to determine whether the amount of soil that was separated into the different particle sizes categories varied between the habitats. Factors of the model included habitat (dry, wet) and sieve sizes $(<0.063 \mathrm{~mm} ; 0.064-$ $0.125 \mathrm{~mm} ; 0.126-0.25 \mathrm{~mm} ; 0.251-0.50 \mathrm{~mm} ; 0.51-1.0 \mathrm{~mm} ; 1.1-2.0 \mathrm{~mm} ; 2.1-4$ $\mathrm{mm} ; 4.1-8 \mathrm{~mm}$ and $>8.1 \mathrm{~mm})$. We used a Pearson's Chi-square test to determine how plant species composition varied between the habitats (dry, wet). We then used a Mann-Whitney $\mathrm{U}$ test to determine if plant species numbers varied between habitats (dry, wet). Finally, we used a $t$-test to determine whether there were differences in plant biomass between these habitats (dry, wet).

Secondly, we were interested in the extent to which the burrowing activity of the different mole-rat species altered the chemical and physical characteristics of the soil. To explore this, we used a 2-way ANOVA to determine how the different soil nutrient concentrations (i.e. $\mathrm{N}, \mathrm{P}, \mathrm{Ca}, \mathrm{K}, \mathrm{Mg}, \mathrm{Na}$ ) varied between soil type (mound-soil and undisturbed soil) and habitat (dry, wet). We used a 3-way ANOVA to determine how the amount of soil separated into the different particle sizes categories varied between soil type (mound-soil and undisturbed soil), habitat (dry, wet) and sieve size $(<0.063 \mathrm{~mm}$; $0.064-0.125 \mathrm{~mm} ; 0.126-0.25 \mathrm{~mm} ; 0.251-0.50 \mathrm{~mm} ; 0.51-1.0 \mathrm{~mm} ; 1.1-2.0 \mathrm{~mm}$; $2.1-4 \mathrm{~mm} ; 4.1-8 \mathrm{~mm}$ and $>8.1 \mathrm{~mm}$ ). Finally, we used a 2-way ANOVA to determine 
how soil compactness varied between sample location (fresh mounds, old mounds, mound vicinity and intermound area) and habitat (dry, wet).

Our third set of questions focused on how mole-rat burrowing activity modified vegetation at large and small spatial scales. At a large scale, we compared the combined vegetation modifications in all quadrats between plots with and without mounds. For the small spatial scale, we limited our analyses to data collected in plots with mounds. For these data, we compared the vegetation in quadrats with and without mounds. To determine how mound presence (presence, absence) and habitat (dry, wet) influenced plant biomass, we used a 2-way ANOVA. Furthermore, we used a linear regression to explore how plant biomass varied in relation to number of mounds and the proportion of the area covered by mounds within quadrats. We then used a Pearson's Chi-square test to determine how the presence of mole-rats influenced plant species composition. In addition, we used a Pearson's Chi-square test to determine how the number of mounds and the proportion of the area covered by mounds within quadrats affected plant species composition. Data for these analyses were categorised. We used a 2-way ANOVA to determine how plant species number varied with mole-rat presence (presence, absence) and habitat (dry, wet). For the dry habitat, we used a linear regression to determine how the number of mounds and the proportion of the area covered by mounds within quadrats influenced plant species numbers. For the wet habitat, we used a Spearman Rank correlation to determine the relationship between the number of mounds or the proportion of the area covered by mounds within quadrats and plant species numbers. As plant species varied between the two habitats, we 
analysed each habitat separately where necessary. Where data did not meet the assumptions of parametric statistical tests, appropriate transformations were performed.

\section{Results}

\section{Habitat differences}

Of the six soil nutrients that we tested, only calcium and magnesium were similar between the habitats (Supplementary Table 1). In addition, we did not find differences in the soil particle sizes between the two habitats $\left(F_{1,342}=0.30 ; P=0.59\right)$. Not surprisingly, there was a significant difference between the soil particle sizes and the various sieve sizes $\left(F_{8,342}=2098.31 ; P<0.0001\right)$. However, the dry habitat had significantly finer soil particles than the wet habitat (Habitat $x$ sieve sizes effect: $F_{8,342}=2.27 ; P=0.02$ ).

Finally, the compactness of the soil was similar in the two habitats $\left(t_{38}=0.95, P=0.35\right)$.

In total, we recorded 61 different plant species in the study area, consisting of 52 forb species and nine grass species. Of the recorded 61 plant species only seven were shared between the two habitats $\left(X^{2}{ }_{16}=332.30 ; P<0.0001\right.$; Supplementary Table 2$)$. However, the two habitats did not differ in either plant biomass (square roottransformation: $\left.t_{18}=0.33, P=0.75\right)$ or plant species richness $(Z=-1.512, \mathrm{~N}=20, P=$ $0.13)$.

\section{Soil data}

\section{Chemical properties}

The amount of nitrogen and magnesium was significantly higher in mound-soils compared to undisturbed soils (Table 1). Similar trends were found for calcium, 
Table 1 Results of two-way ANOVAs of the effects of habitat and soil type on soil nutrient contents at the Wayland Flower Reserve, Darling, South Africa. Statistical significances are indicated in italics. ${ }^{\S}$ denotes log transformation.

\begin{tabular}{|c|c|c|c|c|}
\hline Source of variation & $\mathrm{df}$ & MS & $\mathrm{F}$ & $P$ \\
\hline \multicolumn{5}{|l|}{ Nitrogen } \\
\hline Habitat & 1 & 0.007 & 3.52 & 0.066 \\
\hline Soil type & 1 & 0.012 & 5.85 & 0.019 \\
\hline Habitat x soil type & 1 & 0.002 & 0.84 & 0.364 \\
\hline Error & 56 & 0.002 & & \\
\hline \multicolumn{5}{|l|}{ Phosphor } \\
\hline Habitat & 1 & 65.121 & 3.82 & 0.056 \\
\hline Soil type & 1 & 0.176 & 0.01 & 0.919 \\
\hline Habitat $x$ soil type & 1 & 8.748 & 0.51 & 0.477 \\
\hline Error & 56 & 17.066 & & \\
\hline \multicolumn{5}{|l|}{ Calcium } \\
\hline Habitat & 1 & 652540 & 8.56 & 0.005 \\
\hline Soil type & 1 & 234525 & 3.08 & 0.085 \\
\hline Habitat x soil type & 1 & 184946 & 2.43 & 0.125 \\
\hline Error & 56 & 76239 & & \\
\hline \multicolumn{5}{|l|}{ Potassium $^{\$}$} \\
\hline Habitat & 1 & 5.642 & 52.63 & $<0.001$ \\
\hline Soil type & 1 & 0.362 & 3.37 & 0.072 \\
\hline Habitat $x$ soil type & 1 & 0.022 & 0.21 & 0.650 \\
\hline Error & 56 & 0.107 & & \\
\hline \multicolumn{5}{|l|}{ Magnesium } \\
\hline Habitat & 1 & 248885 & 6.39 & 0.014 \\
\hline Soil type & 1 & 189528 & 4.87 & 0.031 \\
\hline Habitat $x$ soil type & 1 & 94248 & 2.42 & 0.125 \\
\hline Error & 56 & 38924 & & \\
\hline \multicolumn{5}{|l|}{ Sodium $^{\$}$} \\
\hline Habitat & 1 & 6.924 & 15.59 & $<0.001$ \\
\hline Soil type & 1 & 1.557 & 3.51 & 0.066 \\
\hline Habitat $x$ soil type & 1 & 0.645 & 1.45 & 0.233 \\
\hline Error & 56 & 0.444 & & \\
\hline
\end{tabular}


potassium and sodium, although these differences were not significant. Mole-rats did not affect on the amount of phosphorus in the soil, but there were significant habitat effects on various soil nutrients (Table 1). We did not detect significant interactive effects between habitat and soil type (i.e. mound-soil and undisturbed soil) (Table 1).

\section{Physical properties}

Table 2 Results of a three-way ANOVA of the effects of habitat, soil type and sieve sizes on frequency of soil particle sizes at the Wayland Flower Reserve, Darling, South Africa. Statistical significances are indicated in italics.

\begin{tabular}{lcccc}
\hline Source of variation & df & MS & $F$ & $P$ \\
\hline Habitat & 1 & 0.293 & 0.08 & 0.775 \\
Soil type & 1 & 0.332 & 0.09 & 0.761 \\
Sieve sizes & 8 & 9616.864 & 2676.46 & $<0.001$ \\
Habitat x soil type & 1 & 0.317 & 0.09 & 0.767 \\
Habitat x sieve sizes & 8 & 3.094 & 0.86 & 0.549 \\
Soil type $x$ sieve sizes & 8 & 96.922 & 26.97 & $<0.001$ \\
Habitat $x$ soil type $x$ sieve sizes & 8 & 12.607 & 3.51 & $<0.001$ \\
Error & 504 & 3.593 & & \\
\hline
\end{tabular}

Soil particles were finer when mole-rats were present (Table 2). Not surprisingly, there was also a significant difference between the soil particle sizes and the various sieve sizes (Table 2). Furthermore, mound-soil excavated in the wet habitat by Cape molerats had finer soil particles than the mound-soil excavated by common mole-rats in the dry habitat (Table 2). However, soil type and habitat as single factors, habitat $x$ sieve sizes, and habitat $x$ soil type did not affect soil particle sizes (Table 2). We found no 
habitat-effect on the compactness of soils $\left(F_{1,152}=2.84 ; P=0.09\right)$. As expected, compactness gradually decreased from intermound areas, mound vicinity, old mounds to fresh mounds $\left(F_{3,152}=43.81 ; P<0.0001\right)$. Additionally, mound soil of Cape mole-rats was more compact than common mole-rat mound soils. This was even despite soil compactness gradually decreasing from intermound areas, mound vicinity, old mounds to fresh mounds in both habitats $\left(F_{3,152}=3.80 ; P=0.01\right)$.

\section{Large spatial-scale data}

Plant biomass

Generally, plant biomass did not differ between the habitats (square root-transformation: $\left.F_{1,36}=0.80, P=0.38\right)$. However, overall the presence of mole-rats lowered mean plant biomass (square root-transformation: $F_{1,36}=4.02, P=0.053$ ). Furthermore, in the dry habitat, common mole-rats significantly decreased plant biomass. In contrast, Cape mole-rats had no effect on plant biomass in the wet habitat (Habitat x mole-rat presence/absence effect: square root-transformation: $F_{1,36}=5.88, P=0.02$; Fig. 2 ). Additionally, we found a positive correlation in the dry habitat between the number of common mole-rat mounds and plant biomass $\left(F_{1,8}=6.58 ; R^{2}=0.451 ; P=0.03\right.$; Fig. 3A). In contrast, the number of Cape mole-rat mounds had no impact on plant biomass in the wet habitat $\left(F_{1,8}=0.47 ; R^{2}=0.055 ; P=0.51 ;\right.$ Fig. $\left.3 \mathrm{~A}\right)$. 


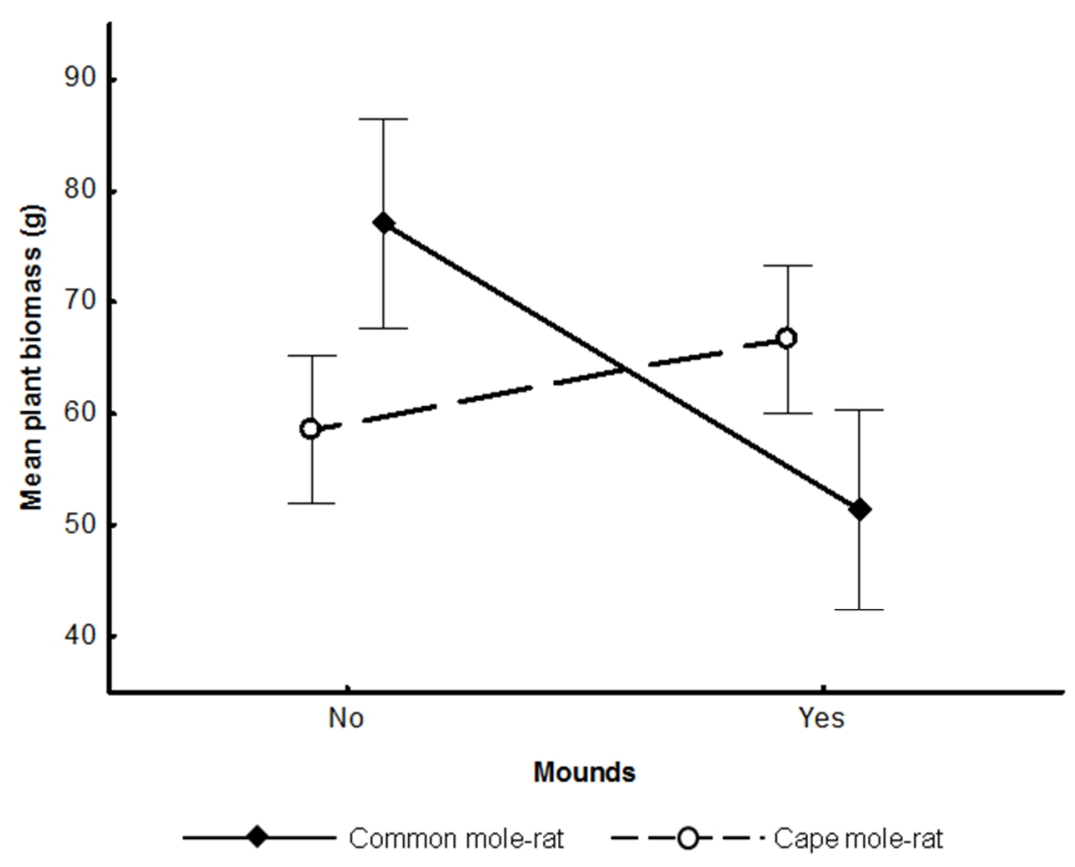

Figure 2 Mean plant biomass (in g) in areas with and without mole-rat mounds for common mole-rats (solid diamonds) and Cape mole-rats (open circles). Error bars represent SD.

\section{Plant species composition}

We found higher numbers of $L$. multiflorum, Avena barbata and Lessertia rigida in the wet habitat when Cape mole-rats were present $\left(X^{2}{ }_{13}=30.51 ; P=0.004\right)$. Additionally, higher number of their mounds resulted in a greater abundance of high quality grass species such as P. clandestinum, C. dactylon and L. multiflorum and hence Poaceae $\left(X^{2}{ }_{52}=274.95 ; P<0.0001\right)$. In contrast, the presence of common mole-rats had no effect on plant species composition in the dry habitat $\left(X^{2}{ }_{11}=12.42 ; P=0.33\right)$. However, a greater number of their mounds increased the abundance of $L$. multiflorum, $C$. 
dactylon and A. barbata but also T. pratense, and thus Poaceae and Fabaceae $\left(X^{2}{ }_{33}=\right.$ 98.94; $P<0.0001)$.
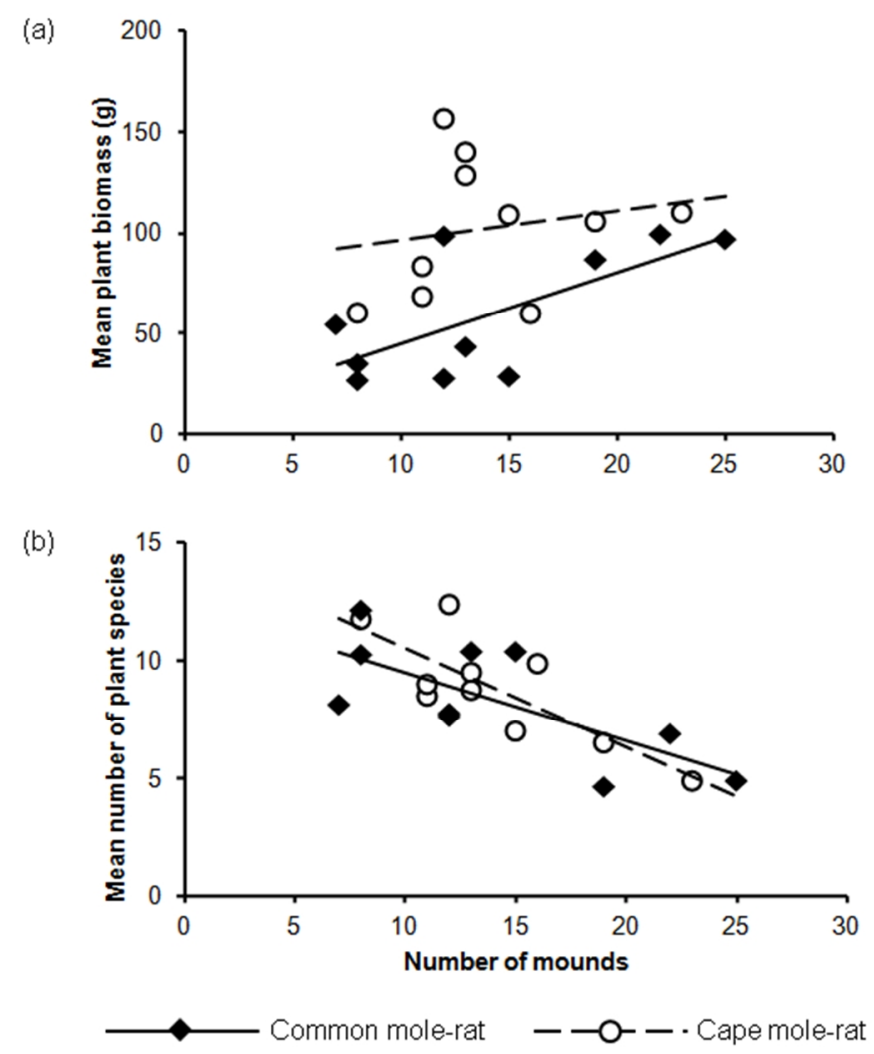

Figure 3 Mean plant biomass (in g, Fig. A) and mean number of plant species (Fig. B) in relation to the number of mole-rat mounds excavated by common mole-rats (solid diamonds) and Cape mole-rats (open circles).

\section{Plant species richness}

The presence of mole-rats significantly increased plant species richness in both habitats $\left(F_{1,36}=5.85 ; P=0.02\right)$. However, species richness did not differ between the dry and wet habitats $\left(F_{1,36}=1.30 ; P=0.26\right)$. Furthermore, the interaction between the presence/absence of mole-rats and the habitat did not influence large scale plant 
species richness (Habitat $x$ mole-rat presence/absence effect: $F_{1,36}=0.20 ; P=0.66$ ). Interestingly, a rising number of mounds ultimately led to a decline of plant species richness in the dry habitat $\left(F_{1,8}=8.52 ; R^{2}=0.52 ; P=0.02\right.$; Fig. $\left.3 \mathrm{~B}\right)$ and a marginally non-significant decline in the wet habitat $(t=2.14 ; R=0.60 ; P=0.06$; Fig. 3B $)$.

\section{Small spatial-scale data}

Plant biomass

Plant biomass was greater in the wet compared to the dry habitat (Supplementary Table 3). We did not find an impact of the presence of mole-rats nor the interaction between the presence of mole-rats and habitat on small-scale plant biomass (Supplementary Table 3). The proportion of the area covered by mounds within quadrats did not affect small-scale plant biomass, in either the dry (square root-transformation: $F_{1,8}=3.95 ; R^{2}=$ $0.33 ; P=0.08$ ) or wet habitat (square root-transformation: $F_{1,8}=2.35 ; R^{2}=0.20 ; P=$ $0.51)$.

\section{Plant species composition}

Mole-rat mounds had no effect on small-scale plant species composition (dry habitat: $X^{2}{ }_{11}=10.84, P=0.46$; wet habitat: $\left.X^{2}{ }_{13}=4.10, P=0.99\right)$ However, an increase in the area covered by mounds within quadrats significantly altered the plant species composition in both the dry $\left(X^{2}{ }_{55}=88.93 ; P=0.003\right)$ and wet habitat $\left(X^{2}{ }_{78}=122.13 ; P=\right.$ 0.001 ). As a result, we found a higher abundance of $P$. clandestinum, $A$. barbata and $L$. rigida in both habitats. 


\section{Plant species richness}

The habitats did not differ in small-scale plant species richness $\left(F_{1,36}=0.55 ; P=0.46\right)$. Richness was also not affected by the presence of mounds $\left(F_{1,36}=0.06 ; P=0.81\right)$ or by the interactive effect of the presence of mounds and habitat (Mound presence/absence $\mathrm{x}$ habitat effect: $\left.F_{1,36}=0.01 ; P=0.92\right)$. Additionally, the proportion of the area covered by mounds within quadrats did not affect richness, in either the dry $\left(F_{1,8}=2.84 ; R^{2}=\right.$ $0.261 ; P=0.13)$ or wet habitat $(t=0.07 ; R=0.024 ; \mathrm{N}=10 ; P=0.95)$.

\section{Discussion}

Subterranean rodents from biomes in North and South America, Europe and Asia can be major drivers of ecosystems and are therefore considered to be ecosystem engineers (e.g., Reichman \& Seabloom, 2002). Our study indicates that the impacts of mole-rats ultimately alter plant community dynamics, suggesting that they act as ecosystem engineers within African biomes. Specifically, we found that the soil of molerat mounds had higher levels of nitrogen and magnesium and to a lesser degree higher calcium, potassium and sodium compared to undisturbed soils. Furthermore, mound soil was finer and less compact than undisturbed soils. These soil property changes potentially contribute to the vegetation modifications found in areas where mole-rats occur. In addition, mole-rats may also have directly and indirectly altered the vegetation. For instance, aboveground plant biomass was lower in areas where mole-rats were present. Furthermore, mole-rat burrowing and foraging activities changed plant species composition. Most importantly, plant species richness was greater in presence of molerats, although in areas of extensive soil disturbance plant species numbers declined. 
In our study, the soil of mole-rat mounds had higher nutrient levels compared to undisturbed soils. This is similar to the findings in other subterranean rodents (e.g., Kerley et al., 2004; Sherrod \& Seastedt, 2001). An increase in nutrient levels may be due to the burial of vegetation by mounds, which results in local nutrient 'hot spots' (Sherrod \& Seastedt, 2001). This improved resource environment may promote plant growth and change both plant species composition and diversity. In our study we recorded higher numbers of $A$. barbata, L. multiflorum and $P$. clandestinum, which are generally 'nitrogen-loving grasses' (K.P. Kirkman, pers. comm.), in the nitrogen-rich soils in areas with mole-rat mounds. However, it is unlikely that decomposing buried vegetation was the cause of the high nutrient content of mound soils in our study as we collected samples from fresh mounds that were at the most, one or two days old. Instead, we suggest that, similar to pocket gophers, the higher nutrient levels may have resulted from soil being mixed up with decomposed uneaten food caches and deposed urine or faeces before it was excavated (e.g., Huntly \& Inouye, 1988). Both mole-rat species in our study cache geophytes in their burrow systems (Lovegrove \& Jarvis, 1986).

In addition to altering nutrient levels, we found that the majority of soil particles in mounds were finer than those found in undisturbed soils. Furthermore, the burrowing activities of mole-rats lowered the compactness of soils. Finer and looser mound soils might enhance both infiltration and water-holding capacity (Plaster, 2008) and thus encourage plant growth. However, we did not assess rates of water percolation into the soil. Furthermore, the finer texture of mound soils might be due to migration of clay 
particles down the profile or by weathering of coarser particles in-situ in the subsoil (Plaster, 2008).

In contrast to our prediction, overall plant biomass was lower in areas where molerats were present, especially in the common mole-rat habitat. This was somewhat surprising based on the many studies that recorded an increase in plant biomass due to the burrowing of subterranean rodents (see Boeken et al., 1995). We expected that the potentially higher water infiltration and enhanced nutrient levels in mole-rat mound soils would encourage plant productivity, as suggested in other studies (Williams et al., 1986). However, the soils found in the study area were generally nutrient rich compared to soils in other more arid mole-rat habitats (N. Hagenah, unpubl. data). Therefore, further increased nutrient levels in this 'nutrient-saturated' area may not result in additional plant growth.

However, our findings are similar to studies where plant biomass was lower in areas inhabited by pocket gophers (Williams \& Cameron, 1986). Pocket gophers bury vegetation while excavating soil, thereby reducing aboveground vegetation (Williams \& Cameron, 1986; Grant et al., 1980). Mole-rats, too, were found to cover vegetation with mound soils which may consequently decrease aboveground plant biomass ( $\mathrm{N}$.

Hagenah, pers. observation). Additionally, both mole-rat species feed to some extent on aboveground plant parts (Reichman \& Jarvis, 1989). Finally, livestock preferred grazing in the common mole-rat habitat (N. Hagenah, pers. observation). Therefore, we suggest that the direct consumption of both belowground plant storage organs and aboveground vegetation combined with the grazing pressure from livestock may have resulted in an overall reduction of plant biomass. 
In our study, we found that mole-rat burrowing and foraging activities changed plant species composition. An increasing number of mole-rat mounds promoted the abundance of grasses (Poaceae) and legumes (Fabaceae). This change in plant species composition may be due to the temporarily improved light conditions in areas of high soil disturbances. Moreover, mole-rats may disrupt the existing vegetation matrix and open up gaps for opportunistic plant species, as has been shown for pocket gophers (Rogers, Hartnett \& Elder, 2001). However, highly disturbed areas not only indicate strong burrowing activities but also reveal significant foraging by mole-rats. Intense foraging and selective feeding by herbivores can have profound impacts on vegetation patterns (Inouye et al., 1987). By decreasing the number of food sources through selective feeding, mole-rats might indirectly increase the relative abundance of other non-preferred plant species such as grasses and legumes. For example, Ellison \& Aldous (1952) reported that grasses and sedges tend to increase where pocket gophers are present. Our study indicates that although grasses (Poaceae) and legumes (Fabaceae) were more abundant where mole-rats occurred; mole-rats had no effect on the number of geophytes, which is their main food source in that habitat (N. Hagenah, unpubl. data).

One of the key findings of our study is that plant species richness was higher in the presence of mole-rats. This finding might be particularly important, as the study area is a biodiversity 'hotspot' of high conservation value. However, a high level of disturbance led to a decline in plant species richness. Mole-rats may increase habitat heterogeneity by creating a patchwork of microsites with improved resource characteristics. A greater range of resource conditions for plants is likely responsible for the increase in overall 
plant community richness (Zhang et al., 2003). However, mole-rat soil disturbances may also increase plant species diversity by generating vegetation gaps that benefit subordinate species which otherwise would be ousted by competitively superior species (Jones et al. 2008). Ultimately, the frequency at which these disturbances occur is a key determinant of the degree of impact on plant species diversity. For example, infrequent disturbance may have little or no long-term impact on a plant community (Connell, 1978). In contrast, frequent disturbances could reduce plant species diversity since perennial plants are prevented from establishing (Connell, 1978). In between these two extremes, the highest plant diversity were with intermediate disturbances (Connell, 1978). The results of our study support these predictions as plant species richness was higher in areas with mole-rat disturbance compared to undisturbed areas, but species richness declined when disturbance levels became too high.

Overall, the social common mole-rats appeared to have a bigger impact on plant communities than the solitary Cape mole-rats. The former have a number of individuals moving soil and foraging, resulting in larger home ranges compared to Cape mole-rats that live and forage alone (Davies \& Jarvis, 1986). Consequently, a large area of disturbed soil due to common mole-rats is likely to have a bigger impact on plant communities than a smaller soil disturbance created by Cape mole-rats.

Ultimately, our findings suggest that, like other subterranean rodents in similar ecosystems, mole-rats profoundly alter chemical and physical soil characteristics which in turn interact with abiotic factors and vegetation in complex ways. Specifically, by changing soil properties, mole-rats may indirectly modify plant communities due to the improved resource environment. Mole-rats might also transform vegetation patterns 
through their direct and indirect effects on plant biomass, and both plant species assembly and richness. In fact, mole-rats appear to be a major physical force in the ecosystem in which they occur and their combined ecological effects may aid in the maintenance and conservation of these ecosystems. Ultimately, our findings suggest that mole-rats fulfil the same ecological niche as their ecosystem engineering ecological cognates.

\section{Acknowledgements}

We conducted the study through a permit issued by the Department of Nature Conservation, Western Cape Province. Furthermore, we greatly thank the Duckitt family for allowing us to work on their property. We thank A. Claassens for soil nutrient analyses, and K.I. Meiklejohn for allowing us to use the sieving equipment. L. Duncan, H. Fourie, L. van Heerden, S. Hugo, H. Lutermann, H. Nieuwoudt, H. Place and U. Schlüter assisted in the field. A.M. Shrader provided valuable comments on the manuscript and C.T. Chimimba provided statistical advice. The study was funded through a University of Pretoria post-doctoral fellowship (to NH) and a DST-NRF SARChl Chair of mammal behavioural ecology and physiology (to NCB). Experimental procedures with mole-rats followed the guidelines of the American Society of Mammalogists (ASM; http://www.mammalogy.org/committees/index.asp; Animal Care and Use Committee (1998)), and were approved by the Animal Ethics Committee of the University of Pretoria (AUCC060721-021). 


\section{References}

Andersen, D.C. \& MacMahon, J.A. (1985). Plant succession following the Mount St.

Helens volcanic eruption: facilitation by a burrowing rodent, Thomomys talpoides. Am.

Midl. Nat. 114, 62-69.

Bennett, N.C. \& Faulkes, C.G. (2000). African mole-rats - ecology and eusociality.

Cambridge, Cambridge University Press, 273pp.

Boeken, B., Shachak, M., Gutterman, Y. \& Brand, S. (1995). Patchiness and

disturbance: plant responses to porcupine diggings in the central Negev. Ecography 18, 410-422.

Connell, J.H. (1978). Diversity in tropical rain forests and coral reefs. Science 199, 1302-1310.

Davies, K.C. \& Jarvis, J.U.M. (1986). The burrow systems and burrowing dynamics of the mole-rats Bathyergus suillus and Cryptomys hottentotus in the fynbos of the southwestern Cape, South Africa. J. Zool (Lond.) 209, 125-147.

Desmet, P.G. \& Cowling, R.M. (1999). Patch creation by fossorial rodents: a key process in the revegetation of phytotoxic arid soils. J. Arid Environ. 43, 35-45.

Goldblatt, (1997). Floristic diversity in the Cape Flora of South Africa. Biodivers.

Conserv. 6, 359-377.

Ellison, L. \& Aldous, C.M. (1952). Influence of pocket gophers on vegetation of subalpine grassland in Central Utah. Ecology 33, 177-186.

Grant, W.E., French, N.R. \& Folse, Jr., L.J. (1980). Effects of pocket gopher mounds on plant production in shortgrass prairie ecosystems. Southwest. Nat. 25, 215-224. 
Huntly, N. \& Inouye, R. (1988). Pocket gophers in ecosystems: patterns and mechanisms. Bioscience 38, 786-793.

Inouye, R.S., Huntly, N.J., Tilman, D. \& Tester, J.R. (1987). Pocket gophers (Geomys bursarius), vegetation, and soil nitrogen along a successional sere in east central Minnesota. Oecologia 72, 178-184.

Jackson, C.R., Lubbe, N.R., Robertson, M.P., Setsaas, T.H., van der Waals, J. \& Bennett, N.C. (2007). Soil properties and the distribution of the endangered Juliana's golden mole. J. Zool (Lond.) 274, 13-17.

Jones, C.C., Halpern, C.B. \& Niederer, J. (2008). Plant succession on gopher mounds in western cascade meadows: consequences for species diversity and heterogeneity. Am. Midl. Nat. 159, 275-286.

Kerley, G.I.H., Whitford, W.G. \& Kay, F.R. (2004). Effects of pocket gophers on desert soils and vegetation. J. Arid Environ. 58, 155-166.

Lara, N., Sassi, P. \& Borghi, C.E. (2007). Effect of herbivory and disturbances by tucotucos (Ctenomys mendocinus) on a plant community in the southern Puna Desert. Arct., Antarct. Alp. Res. 39, 110-116.

Lovegrove, B.G. \& Jarvis, J.U.M. (1986). Coevolution between mole-rats (Bathyergidae) and a geophyte, Micranthus (Iridaceae). Cimbebasia 8, 79-85.

Manning, J.C. \& Goldblatt, P. (2007). West Coast. South African wild flower guide. Kirstenbosch, Claremount, Botanical Society of South Africa, 240pp.

Plaster, E.J. (2008): Soil Science and Management. $5^{\text {th }}$ Edition. New York, Delmar Cengage Learning, 495pp. 
Reichman, O.J. \& Jarvis, J.U.M. (1989). The influence of three sympatric species of fossorial mole-rats (Bathyergidae) on vegetation. J. Mammal. 70, 763-771.

Reichman, O.J. \& Seabloom, E.W. (2002). The role of pocket gophers as subterranean ecosystem engineers. Trends Ecol. Evol. 17, 44-49.

Rogers, W.E., Hartnett, D.C. \& Elder B. (2001). Effects of Plains Pocket Gopher (Geomys bursarius) disturbances on Tallgrass-Prairie community structure. Am. Midl. Nat. 145, 344-357.

Sherrod, S.K. \& Seastedt, T.R. (2001). Effects of the northern pocket gopher (Thomomys talpoides) on alpine soil characteristics, Niwot Ridge, CO. Biogeochemistry 55, 195-218.

Skinner, J.D. \& Chimimba, C.T. (2005). The Mammals of the Southern African Subregion. Cambridge, Cambridge University Press, 814pp.

Spencer, S.R., Cameron, G.N., Eshelman, B.D., Cooper, L.C. \& Williams, L.R. (1985). Influence of pocket gopher mounds on a Texas coastal prairie. Oecologia 66, 111-115. Williams, L.R. \& Cameron, G.N. (1986). Effects of removal of pocket gophers on a Texas coastal prairie. Am. Midl. Nat. 115, 216-224.

Williams, L.R., Cameron, G.N., Spencer, S.R., Eshelman, B.D. \& Gregory, M.J. (1986). Experimental analysis of the effects of pocket gopher mounds on Texas coastal prairie. J. Mammal. 67, 672-679.

Zhang, Y., Zhang, Z. \& Liu, J. (2003). Burrowing rodents as ecosystem engineers: the ecology and management of plateau zokors Myospalax fontanierii in alpine meadow ecosystems on the Tibetan Plateau. Mammal. Rev. 33, 284-294. 


\section{Supplementary Tables}

Supplementary Table 1 Results of $t$-tests of the effects of habitat on the soil nutrient contents in the undisturbed areas. Statistical significances are indicated in italics. ${ }^{\S}$ denotes log transformation.

\begin{tabular}{|c|c|c|c|c|c|}
\hline Source of variation & $\begin{array}{c}\text { Mean } \\
\text { Dry habitat }\end{array}$ & $\begin{array}{c}\text { Mean } \\
\text { Wet habitat }\end{array}$ & df & t-value & $\mathbf{P}$ \\
\hline Nitrogen (\%) & 0.15 & 0.11 & 38 & 2.49 & 0.017 \\
\hline Phosphor (mg/kg) & 5.92 & 8.94 & 38 & 2.13 & 0.040 \\
\hline Calcium (mg/kg) & 1096.95 & 1200.40 & 38 & 1.27 & 0.212 \\
\hline Potassium ${ }^{\S}(\mathrm{mg} / \mathrm{kg})$ & 4.73 & 5.39 & 38 & 5.39 & $<0.001$ \\
\hline Magnesium (mg/kg) & 744.05 & 796.60 & 38 & 0.81 & 0.423 \\
\hline Sodium $^{\S}(\mathrm{mg} / \mathrm{kg})$ & 5.64 & 6.14 & 38 & 2.12 & 0.041 \\
\hline
\end{tabular}

Supplementary Table 2 Availability of the different plant species in the wet and dry habitats. The 'other' category comprises all plant species that made up $<1.5 \%$ of the species available.

\begin{tabular}{lcc}
\hline Plant Species & $\begin{array}{c}\text { \% within } \\
\text { Wet habitat }\end{array}$ & $\begin{array}{c}\text { \% within } \\
\text { Dry habitat }\end{array}$ \\
\hline Pennisetum clandestinum & 13.5 & 8.7 \\
Lolium multiflorum & 10.8 & 12.8 \\
Trifolium pratense & 0.2 & 10.4 \\
Cynodon dactylon & 5.3 & 9.8 \\
Lessertia rigida & 3.4 & 3.5 \\
Gymnodiscus capillaris & 4.7 & 3.0 \\
Avena barbata & 1.9 & 4.8 \\
Briza maxima & 5.3 & 0 \\
Heliophila refracta & 5.1 & 0 \\
Lupinus perenne & 4.0 & 0 \\
Eragrostis curvula & 2.9 & 0 \\
Zantedeschia aethiopica & 2.5 & 0 \\
Ehrhartha calycina & 1.7 & 0 \\
Oxalis pes-caprae & 0 & 7.2 \\
Ornithogalum conicum & 0 & 3.1 \\
Arctotheca calendula & 0 & 2.6 \\
other & 38.6 & 34.2 \\
\hline
\end{tabular}


Supplementary Table 3 Results of a two-way ANOVA of the effects of habitat and Mole-rat presence/absence on the mean plant biomass at small scales. Data were square-root transformed prior to the analysis. Statistical significances are indicated in italics.

\begin{tabular}{lcccc}
\hline Source of variation & $\mathrm{df}$ & $\mathrm{MS}$ & $\mathrm{F}$ & $\mathrm{P}$ \\
\hline Habitat & 1 & 60.695 & 15.42 & 0.0004 \\
Mole-rat presence/absence & 1 & 0.016 & 0.004 & 0.95 \\
Mole-rat presence/absence x habitat & 1 & 0.120 & 0.03 & 0.86 \\
Error & 36 & 3.935 & & \\
\hline
\end{tabular}

